\title{
Leber's hereditary optic atrophy: further evidence for a defect of cyanide metabolism?*
}

\author{
T A BERNINGER, ${ }^{1}$ L v MEYER, ${ }^{2}$ E SIESS, ${ }^{3}$, O SCHON, ${ }^{3}$ AND F-D GOEBEL ${ }^{3}$ \\ From the 'University Eye Hospital, Munich; the Institute of Legal Medicine, University of Munich; and the \\ ${ }^{3}$ Medical Policlinic, University of Munich
}

SUMmARY We studied one patient with Leber's optic atrophy (LOA) in the acute stage and 12 at the chronic stage of the disease, and measured the activity of rhodanese in white blood cells and the level of cyanide in whole blood. In the patient with acute disease the blood cyanide level was significantly increased at first. Treatment of this patient with cyanide antagonists reduced his cyanide level, but this was not accompanied by improvement in visual function. Rhodanese activity was normal in all patients, as were the blood cyanide levels in each of the 12 patients at the chronic stage of the disease. These findings suggest a temporary disturbance of cyanide metabolism during the acute phase of the disease in this family. The abnormal metabolic mechanism was not identified.

In 1965 Wilson' observed that in most cases of Leber's optic atrophy (LOA) the severity of the disease could be related to tobacco smoking. Because tobacco is the major exogenous source of cyanide in Europe, he suggested cyanide as a possible precipitant of visual loss in LOA. This impression was reinforced by the observation that optic neuritis occurs as a result of cyanide intoxication from ingestion of bitter cassava in man $^{2.3}$ and in animals. ${ }^{4}$ These findings prompted a search for abnormal cyanide metabolism in LOA.

Wilson' observed significantly increased urinary thiocyanate excretion in healthy smokers as compared with that in non-smokers. By contrast no difference between smokers and non-smokers was found in LOA patients, suggesting that patients with LOA are unable to respond to an increased intake of cyanide by increased detoxification. Rogers ${ }^{5}$ also observed relatively low levels of thiocyanate in patients with LOA.

Significantly reduced rhodanese (Ec: 2.8.1.1) activity, the key enzyme for cyanide detoxification, was found by Cagnianut et al. ${ }^{6}$ in the liver

*Parts of the results were presented at the 83rd meeting of the
German Ophthalmology Society and at the ARVO meeting 1987 . Correspondence to T A Berninger, MD, University Eye Hospital Munich, Mathildenstrasse 8, 8000 Munich 2, West Germany. parenchymal cells and by Poole and $\mathrm{Kind}^{7}$ in the rectal mucosa of patients with LOA. However, Wilson' reported normal rhodanese levels in the liver, Syme et al. ${ }^{8}$ in the red cells, and Nikoskelainen et al. ${ }^{9}$ in mitochondria of muscle samples of patients with Leber's disease.

These observations prompted this further study of cyanide metabolism in patients with LOA.

\section{Case report}

In mid-January 1985 a 22-year-old male non-smoker noticed decreased vision in the left eye followed by a decrease in the right eye two weeks later. The visual acuity was $20 / 200$ in the right eye and $20 / 300$ in the left eye. The right optic disc of the patient was hyperaemic, with blurred margins. Circumpapillary telangiectatic microangiopathy, tortuosity of the retinal vessels, and swelling of the retinal nerve fibres were apparent. No abnormal vascular permeability was demonstrable by fluorescein angiography. In the left eye the optic disc was blurred only nasally.

At that time general examination (including urine tests), neurological examination, CT scan, and the flash electroretinogram (ERG) were normal. The mother and the grandmother of the patient had also suffered acute visual loss in the 4th decade of life 
and both were more severely affected than the propositus. Cyanide levels were determined according to the method described by Pranitis and Stolman, ${ }^{10}$ as modified by Wicht. ${ }^{11}$ Rhodanese (a mitochondrial enzyme) activity was measured in white blood cells by Sorbo's method. ${ }^{12}$

A significantly increased blood cyanide level of 1.4 $\mu \mathrm{g} / \mathrm{ml}(54 \mu \mathrm{mol} / 1)$ was found in the patient at the first examination (normal level $<0.2 \mu \mathrm{g} / \mathrm{ml}(7.7 \mu \mathrm{mol} / \mathrm{l}$ ). In an attempt to lower the blood cyanide level the patient was treated for two days with $250 \mathrm{mg}$ pDMAP (which forms met-Hb), $600 \mathrm{mg} \mathrm{CO}$-EDTA, $18 \mathrm{~g}$ vitamin $\mathrm{B}_{12}$ (which both complex cyanide), and $375 \mathrm{ml}$ of $8 \%$ sodium thiosulphate infusion (substrate for rhodanese). With this treatment the blood cyanide fell to $0.6 \mu \mathrm{g} / \mathrm{ml}(23 \mu \mathrm{mol} / \mathrm{l})$. Because of cardiac side effects $\mathrm{CO}_{2}$-EDTA was withdrawn. Treatment was continued with sodium thiosulphate, and the cyanide level returned to normal after four weeks (Fig. 1). Treatment was then stopped and the blood cyanide level rose to $0.8 \mu \mathrm{g} / \mathrm{ml}(30.8 \mu \mathrm{mol} / \mathrm{l})$. The visual acuity with each eye gradually deteriorated to $20 / 600$ over the next three months. Treatment with sodium thiosulphate was begun again in July 1985, and cyanide levels returned to normal values. The level remained normal after cessation of treatment (Fig. 1). By September 1985 the visual acuity with each eye remained at $20 / 600$, and the optic discs were pale.

An additional 12 patients with chronic LOA (including the mother of the patient reported on above) were tested. White blood cell rhodanese activities and blood cyanide levels of all these patients were within the normal range.
Discussion

Our observation that the cyanide level was increased in a patient with acute LOA lends further support to the suggestion of Wilson ${ }^{13}$ that there is a defect in cyanide metabolism. We could not induce any improvement in visual acuity despite adequate reduction of the blood cyanide levels. The late onset of the treatment (two weeks after the second eye deteriorated) may explain the absence of visual recovery. It is remarkable that an increased cyanide level was observed only in the acute stage. In each of our chronic cases cyanide levels were normal, and in our patient with the acute disease it returned to normal after the attack. In contrast to the findings of Cagnianut et al. ${ }^{6}$ and Poole and Kind, ${ }^{7}$ none of our patients with LOA showed any reduction in rhodanese activity.

The finding in the patient with the acute disease implies a self-limiting derangement of cyanide metabolism. This would be in accordance with the behaviour of the disease in which acute dysfunction may or may not occur in patients with the abnormal inherited factor and funduscopic abnormalities. ${ }^{14}$ is These observations also imply that a metabolic abnormality may be detected only during the acute stage, and that normal activity of enzymes involved in cyanide metabolism outside the acute stage of the disease would not necessarily exclude abnormal enzyme activity as contributing towards the pathogenesis of the disease.

We thank Professor O-E Lund for his encouragement and support. We are further deeply indebted to Professor A C Bird, Dr C Vesey, and Professor G W Weinstein for their help on the manuscript and

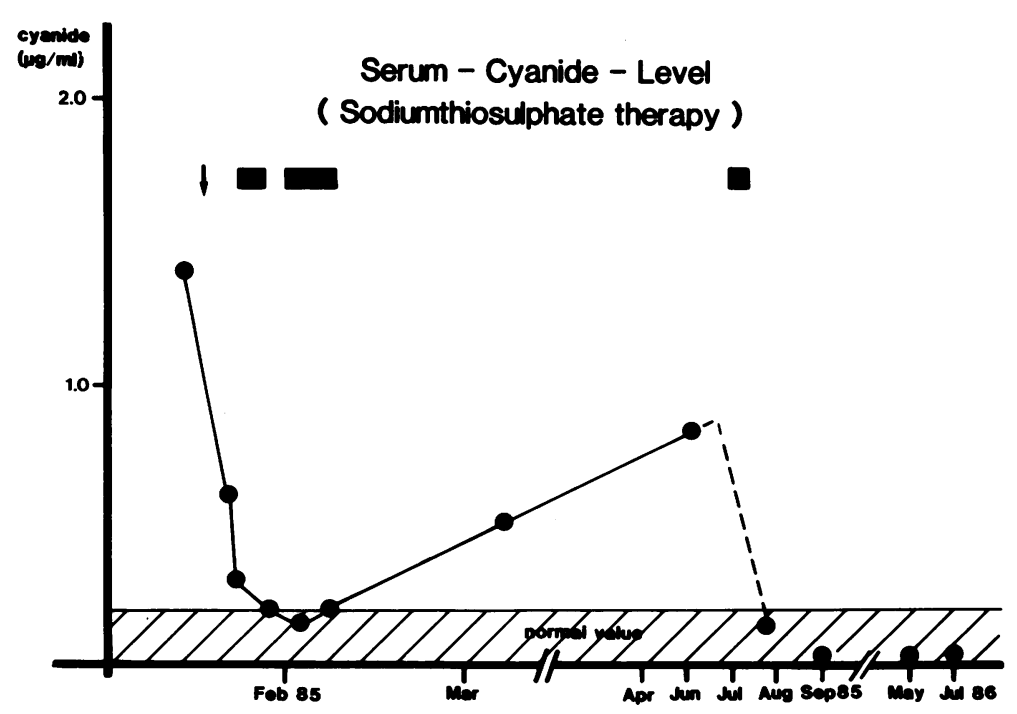

The change of the cyanide level during the therapy is shown. The arrow indicates the initial therapy $(600 \mathrm{mg} \mathrm{CO}$-EDTA, $250 \mathrm{mg}$ $D M A P, 18 \mathrm{~g}$ vitamin $B_{12}, 375 \mathrm{ml}$ of $8 \%$ sodium thiosulphate infusion). The black blocks indicate the treatment with sodium thiosulphate infusion. The first block presents a 4-day treatment, the second and third block an 8-day treatment, of $375 \mathrm{mg}$ of $8 \%$ sodium thiosulphate infusion per day. The visual acuity was 201300 in the right eye and 201 400 in the left eye at the beginning of the treatment. In March 1985 the visual acuity had decreased in the right eye to 201400 and in the left to $20 / 600$ in parallel with the increase of the cyanide level. Just before the third treatment the visual acuity had decreased also in the right eye to $20 / 600$. 
Professor E Aulhorn, Professor A Blankenagel, Dr H Berdjis, and Professor K W Ruprecht for their support.

\section{References}

1 Wilson J. Leber's hereditary optic atrophy: a possible defect of cyanide metabolism. J Clin Sci 1965; 29: 505-15.

2 Osuntokun BO. Ataxic high casava diets in West Afrika. In: Nestel B, Maclutyre R, eds. Chronic casava toxicity. Ottawa: International development research centre, 1973: 127-38.

3 Montgomery RD. The medical significance of cyanogen in plant foodstuffs. Am J Clin Nutr 1965; 17: 103-13.

4 Lessel S. Experimental cyanide optic neuropathy. Arch Ophthalmol 1971; 86: 194-204.

5 Rogers AR. Leber's disease. Aust J Ophthalmol 1977: 5: 111-9.

6 Cagnianut B, Schnebli HP, Rhyner K, Furrer J. Decreased thiosulfate sulfur transferase (rhodanese) in Leber's hereditary optic atrophy. Klin Wochenschr 1984; 62: 850-4.

7 Poole CJM, Kind PRN. Deficiency of thiosulphate sulphur transferase (rhodanese) in Leber's hereditary optic neuropathy. Br Med J 1986; 292: 1229-30.

8 Syme IG, Bronte-Stewart J, Foulds WS, McClure E, Logan R, Stansfield M. Clinical and biochemical findings in Leber's hereditary optic atrophy. Trans Ophthalmol Soc UK 1983; 103: 556-9.

9 Nikoskelainen E, Hassinen IE, Raljarri L, Lang H, Kalmo H. Leber's hereditary optic neuroretinopathy, a mitochondrial disease? Lancet 1984; ii: 1474.

10 Pranitis P, Stolman A. Spectrophotometric determination of cyanide in biological materials. J Forensic Sci 1977; 22: 443-5.

11 Wicht A. Zur Bedeutung der Bildung von Cyanwasserstoff bei Branden. Dissertation, Universitat Munchen, 1982: 26-31.

12 Sorbo BH. Rhodanese. In: Colwick S, Kaplan ON, eds. Methods of enzymology. New York: Academic Press, 1955; 2: 334-5.

13 Wilson J, Linnell JC. Matthews DM. Plasma-cobalamins in neuro-ophthalmological disease. Lancet $1971 ;$ i: 259-61.

14 Nikoskelainen E, Hoyt WF, Nummelin K. Ophthalmoscopic findings in Leber's hereditary optic neuropathy. I. Fundus findings in asymptomatic family members. Arch Ophthalmol 1982; 100: $1597-2$.

15 Nikoskelainen E, Hoyt WF, Nummelin K. The ophthalmoscopic findings in Leber's hereditary optic neuropathy. II. The fundus findings in the affected family members. Arch Ophthalmol 1983: 101: $1059-68$.

Accepted for publication 9 June 1988. 